\title{
COLLIDER RING PARTICLE LOSS TRACKING WITH SSCTRK*
}

\author{
T. Garavaglia, S. K. Kaufmann and R. Stiening \\ Superconducting Super Collider Laboratory ${ }^{\dagger}$ \\ Accelerator Division \\ 2550 Beckleymeade Avenue \\ Daillas, Texas 75237
}

April 1990

\section{DISCLAIMER}

\begin{abstract}
This report was prepared as an account of work sponsored by an agency of the United States Government. Neither the United States Government nor any agency thereof, nor any of their employees, makes any warranty, express or implied, or assumes any legal liability or responsibility for the accuracy, completeness, or usefulness of any information, apparatus, product, or process disclosed, or represents that its use would not infringe privately owned rights. Reference herein to any specific commercial product, process, or service by trade name, trademark, manufacturer, or otherwise does not necessarily constitute or imply its endorsement, recommendation, or favoring by the United States Government or any agency thereof. The views and opinions of authors expressed herein do not necessarily state or reflect those of the United States Government or any agency thereof.
\end{abstract}

\footnotetext{
*Presented at the International Industrial Symposium on the Super Collider, Miami Beach, Florida, March 14-16, 1990.

†Operated by the Uiviversities Research Association, Inc., for the U.S. Department of Energy under Contract No. DE-AC02-89ER40486.
} 


\title{
COLLIDER RING PARTICLE LOSS TRACKING WITH SSCTRK
}

\author{
T. Garavaglia, S.K. Kauffmann and R. Stiening \\ Superconducting Super Collider Laboratory* \\ 2550 Beckleymeade Ave, MS 1047 \\ Dallas, Texas 75237-3946
}

\begin{abstract}
The SSCTRK numerical simulation tracking code has been used to study the benefit of increasing the SSC dipole magnet aperture from 4 to $5 \mathrm{~cm}$. This study has been carried out for both hypothetical highly corrected and plausibly corrected machines, the former having no systematic multipole errors and chromaticity identically zero. The choice of tune values, phase advance per cell, random multipole errors, systematic multipole errors and chromaticity (for the plausibly corrected machines), closed orbit error, the criterion for particle loss, etc. are set forth in detail. Runs of $10^{5}$ turns and $3 \times 10^{6}$ turns are presented together with the approximate dynarnic apertures they yield from their particle loss patterns.
\end{abstract}

This presentation describes the application of D.M. Ritson's numerical simulation particle tracking code SSCTRK to particle loss studies of the main SSC collider rings under injection conditions. The requirement that the beam survive the long $(30+$ minutes) injection dwell without significant loss is a central consideration in determining such basic collider ring parameters as cell length, injection energy, and magnet aperture. At the time this study was initiated, it appeared probable that the half cell length would be shortened to $90 \mathrm{~m}$ and the injection energy raised to $2 \mathrm{TeV}$. These parameters were incorporated into all the SSCTRK runs made.

The random multipole errors (Table 1) of $4 \mathrm{~cm}$ SSC dipoles (arising principally from random variations in the placement of the current carrying cable, often called "geometrical" errors) were put into SSCTRK from the values estimated in delail in the Preliminary Report of the Magnet-Errors Working Group of the SSC Aperture Workshop (SSC-7). (The method used in this document entailed appropriate scaling of results from production measurements of other superconducting accelerator dipoles.) The SSC-7 value for the random regular sextupole error was, however, reduced by a factor of five for input into SSCTRK, on the assumption that the dipoles would be sorted on this random error.

\footnotetext{
* Operated by the Universities Research Association, Inc., for the U.S. Department of Energy under Contract No. DE-AC02-89ER40486.
} 
Random multipole errors for conceivable $5 \mathrm{~cm}$ SSC dipoles were put into SSCTRK by scaling the $4 \mathrm{~cm}$ values according to the formula

$$
\sigma\left(B_{n}^{\prime}, A_{n}^{\prime}\right)=\sigma\left(B_{n}, A_{n}\right)(5 / 4)^{-\left(n+\frac{1}{2}\right)}
$$

suggested by scaling considerations discussed in SSC-7.

TABLE 1

$4 \mathrm{~cm}$ and $5 \mathrm{~cm}$ dipole random multipole distributions used in SSCTRK simulations

\begin{tabular}{|c|c|cc|c|}
\hline $\begin{array}{l}\text { Standards } \\
\text { Deviations }\end{array}$ & $4 \mathrm{~cm}$ dipole & $5 \mathrm{~cm}$ dipole & Notes \\
\hline$\sigma \mathrm{A} 1$ & $0.7 \quad$ units & 0.49 & units & \\
$\sigma \mathrm{B} 1$ & 0.7 units & 0.49 & units & \\
\hline$\sigma \mathrm{A} 2$ & 0.62 units & 0.35 & units & Obtained by sorting \\
$\sigma \mathrm{B} 2$ & 0.4 units & 0.23 & units & \\
\hline$\sigma \mathrm{A} 3$ & 0.69 units & 0.32 & units & \\
$\sigma \mathrm{B} 3$ & 0.34 units & 0.16 & units & \\
\hline$\sigma \mathrm{A} 4$ & 0.14 units & 0.051 units & \\
$\sigma \mathrm{B} 4$ & 0.59 units & 0.22 & units & \\
\hline$\sigma \mathrm{A} 5$ & 0.16 units & 0.047 & units & \\
$\sigma \mathrm{B} 5$ & 0.059 units & 0.017 units & \\
\hline$\sigma \mathrm{A} 6$ & 0.034 units & 0.008 & units & \\
$\sigma \mathrm{B} 6$ & 0.075 units & 0.018 units & \\
\hline
\end{tabular}

The values of all multipoles with $n>6$ were taken to be zero to speed the computation.

The systematic multipole errors (Table 2) in these dipoles which are allowed by their symmetry are the even regular multipoles, B2, B4, B6, etc. Thest systematic errors can arise from superconductor persistent current magnetization or systematic variances in the dipole coil cross section from that designed. It is assumed that the latter will be negligible compared with the former, which, for the $4 \mathrm{~cm}$ dipoles, have been taken from the values given in "Progress on Magnetization Calculations for the SSC Magnets", presentation to the MSIM, 17 January 1990 , by M.A. Green, for a superconducting filament diameter of 6 microns. Furthermore, in SSCTRK, the large ( -3 units) systematic B2 value is subject to a correction which effectively eliminates it. The systematic B4 is not input into SSCTRK at its full value of 0.2 units, but at one quarter of that, an estimated reduction one might hope to achieve with preset decapole correction magnets.

Systematic multipole errors not allowed by the symmetry of the dipoles can uccur if that symmetry is broken, for example, by unpaired buswork, by coil ends and Sagitta, or gravitational distortion. Reducing such unallowed systematic multipole errors to 0.05 units is considered to be a challenging task (several centimeters of unpaired buswork can already produce comparable values, all of the same sign), so this value was input into SSCTRK for the unallowed systematics. 
Exceptions were made for the systematic B1 and A1, which it was assumed are tuned to zero.

TABLE 2

$4 \mathrm{~cm}$ dipole systematic multipole errors used in SSCTRK simulations

\begin{tabular}{|c|c|c|}
\hline Multipole & & SSCTRK Simulation Value \\
\hline $\begin{array}{l}<\mathrm{A} 1> \\
\langle\mathrm{B} 1>\end{array}$ & $\begin{array}{l}0.00 \text { units } \\
0.00 \text { units }\end{array}$ & $\begin{array}{l}\text { (tuned to } 0 \text { ) } \\
\text { (tuned to } 0 \text { ) }\end{array}$ \\
\hline $\begin{array}{l}\langle A 2\rangle \\
\langle B 2\rangle\end{array}$ & $\begin{array}{r}0.05 \text { units } \\
-3.00 \text { units }\end{array}$ & (effective SSCTRK correction to 0) \\
\hline $\begin{array}{l}\langle A 3\rangle \\
\langle B 3\rangle\end{array}$ & $\begin{array}{l}0.05 \text { units } \\
0.05 \text { units }\end{array}$ & \\
\hline $\begin{array}{l}\langle\mathrm{A} 4\rangle \\
\langle\mathrm{B} 4\rangle\end{array}$ & $\begin{array}{l}0.05 \text { units } \\
0.05 \text { units }\end{array}$ & (tuned from 0.2 ) \\
\hline $\begin{array}{l}<A 5\rangle \\
\langle\mathrm{B} 5\rangle\end{array}$ & $\begin{array}{l}0.05 \text { units } \\
0.05 \text { units }\end{array}$ & \\
\hline $\begin{array}{l}\langle A 6\rangle \\
\langle B 6\rangle\end{array}$ & $\begin{array}{r}0.05 \text { units } \\
-0.07 \text { units }\end{array}$ & \\
\hline
\end{tabular}
formula

Systemic multipoles for a $5 \mathrm{~cm}$ aperture dipole were obtained by using the scaling

$$
\left\langle B_{n}^{\prime}, A_{n}^{\prime}\right\rangle=\left\langle B_{n}, A_{n}\right\rangle(5 / 4)^{-n}
$$

on the above Table 2 .

We consider the systematic multipole values of Table 2 (and its scaling to the $5 \mathrm{~cm}$ aperture case) to be plausible for what might reasonably be achieved in the machine in the months after its commissioning. We also consider it plausible that chromaticity can be corrected to 5 units. In the longer term, it might be envisioned that all the systematic multipoles of Table II could be compensated by suitable delicate fine tuning of the correction magnets, and the chromaticity corrected to nearly zero. We have accordingly split our SSCTRK runs into two classes, the first being plausibly corrected machines, with systematic multipoles corresponding to Table 2 , together with $x$ and $y$ chromaticity of +5 units, and the second being highly corrected machines, with all systematic multipoles set to zero (with the exception of $\langle\mathrm{B} 2\rangle$, which is anyway effectively eliminated by the correction we select in SSCTRK) together with chromaticity zero.

The tune values for all the SSCTRK runs presented here is Qx=XXX. 425 and $\mathrm{Q} y=\mathrm{XXX} .410$, chosen on the basis of Fermilab Main Ring and Tevatron experience. This operating point is clear of all resonances up to 8th order (see Figure 1). 


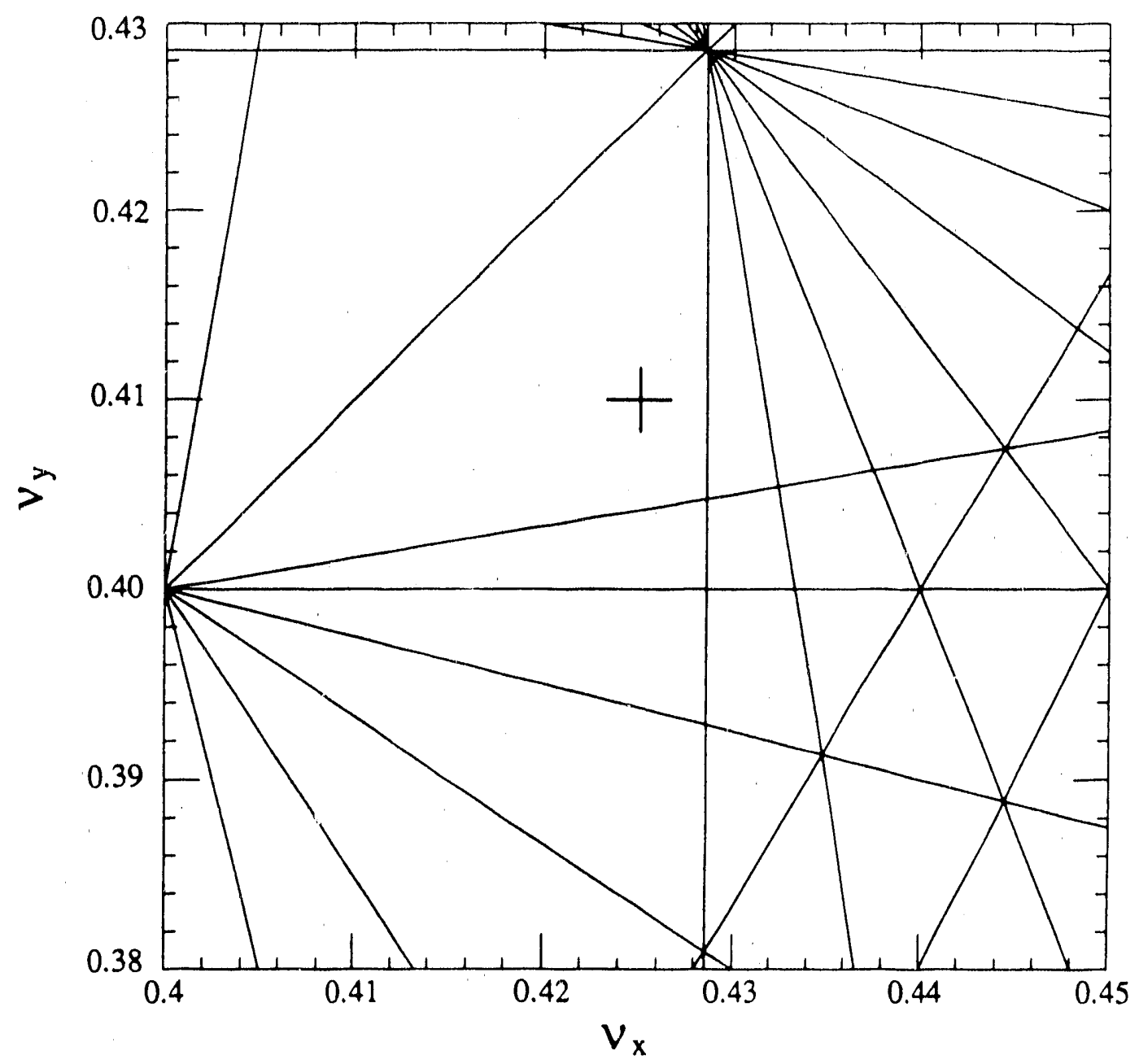

Figure 1. The cross marks the operating point chosen for SSCTRK simulation. All resonance lines up to 8 th order are shown.

The half cell length chosen is $90 \mathrm{~m}$, and the phase advance per cell is $95^{\circ}$. This is a little more than the design $90^{\circ}$, which it was feared might cause a damaging beam-lattice resonance (no convincing evidence for such an effect was seen when $90^{\circ}$ phase advance runs were made).

Magnetic elements are taken to be misaligned with respect to the closed orbit by an rms deviation of $1 \mathrm{~mm}$.

The RF voltage is taken as $20 \mathrm{MV}$ and the frequency as 375 megahertz. The fractional momentum deviation of the particles in these runs is taken as $5 \times 10^{-4}$.

Power supply ripple is not included in these runs - other runs suggest that, at the tune operating point chosen, it is easily feasible to reduce it to a value which doesn't affect the results.

The SSCTRK code doesn't presently incorporate interaction regions. It is not expected that this omission will significantly alter the results presented here, as the interaction region beta values during the injection dwell are modest. 
The SSCTRK code doesn't simulate the details of diagnostic and correction magnet systems. When a correction mode is selected, SSCTRK computes the mean value across the machine of the error multipole in question and then subtracts the appropriate offset value (often the mean itself) from that multipole's error values in each element. (These are "zeroth harmonic" corrections - recently a "first harmonic" correction capability has also been incorporated into the code.) In the runs presented here, this type of correction is performed for $\mathrm{B} 1, \mathrm{~B} 2$, and $\mathrm{A} 1$.

The runs presented here are of a particle loss nature, with a circulating particle being considered lost if its distance from the closed orbit can possibly exceed $\sqrt{2} \times 15 \mathrm{~mm}$ during a drift between thin elements (particles are checked for loss every two and half cells by evaluating the sum of the appropriate $x$ and $y$ Courant-Snyder emittance invariants). Particles are always launched with equal maximum $x$ and $y$ amplitudes with respect to the closed orbit, and angle equal to zero. When a particle is lost, a new particle (its "daughter") is launched at the same position in the machine where the "parent" particle was lost, but having initial maximum $x$ and $y$ amplitudes $1 \mathrm{~mm}$ less than the initial maximum amplitudes of the "parent".

For the runs presented here, the "first generation" of particles is always launched at the same defocusing quadrupole of the machine, with $x$ and $y$ maximum amplitude equal and gridded at the four values $10 \mathrm{~mm}, 101 / 3 \mathrm{~mm}, 102 / 3 \mathrm{~mm}$ and $11 \mathrm{~mm}$. Particles running at such high amplitudes see a very bad field region and are rapidly lost. However, each subsequent generation is stepped in by $1 \mathrm{~mm}$ in initial maximum $x$ and $y$, and within a few tens of thousands of turns, losses become quite infrequent, as the pattern of sufficiently high generation running particles edges on (indeed, defines) the dynamic aperture.

The random multipole errors for a machine are simulated using a random number generator. In order to avoid getting an especially fortunate or unfortunate sequence of random numbers defining the machine, many machines (typically 16) are simultaneously simulated by choosing different seeds for the random number generator. Each machine is then run with four particles and their subsequent stepped-in generations, as described above. On a vectorizing supercomputer, all the particles in all the simulated machines can be run in parallel. One may summarize the results of such a run with a particle loss plot, where each point represents the number of turns a particle completed before it was lost versus its initial maximum $x=y$ launch amplitude. The left hand boundary of the pattem of such particle loss points may be roughly identified as the dynamic aperture, at least for the number of turns computed.

The injection dwell of $30+$ minutes corresponds to around $10^{7}$ turns. Running 64 particles in parallel (4 particles each in 16 machines) for this many turns in SSCTRK requires of order $100 \mathrm{CPU}$ hours of Cray 2 or SX2 supercomputer time. Running only 8 machines ( 32 particles) cuts down on Cray 2 CPU time by over $30 \%$, so the really long runs were made with this option. However, it was observed that particle losses become very infrequent after $10^{5}$ turns, which only require about one CPU hour of supercomputer time. Indeed the dynamic aperture values which are to be gleaned from 100,000 turn runs with 16 machines are usually not far from those which may be read from multi-million turn runs with 8 machines.

Below we present particle loss plots for 4 and $5 \mathrm{~cm}$ magnet aperture machines which are highly corrected and plausibly corrected. 


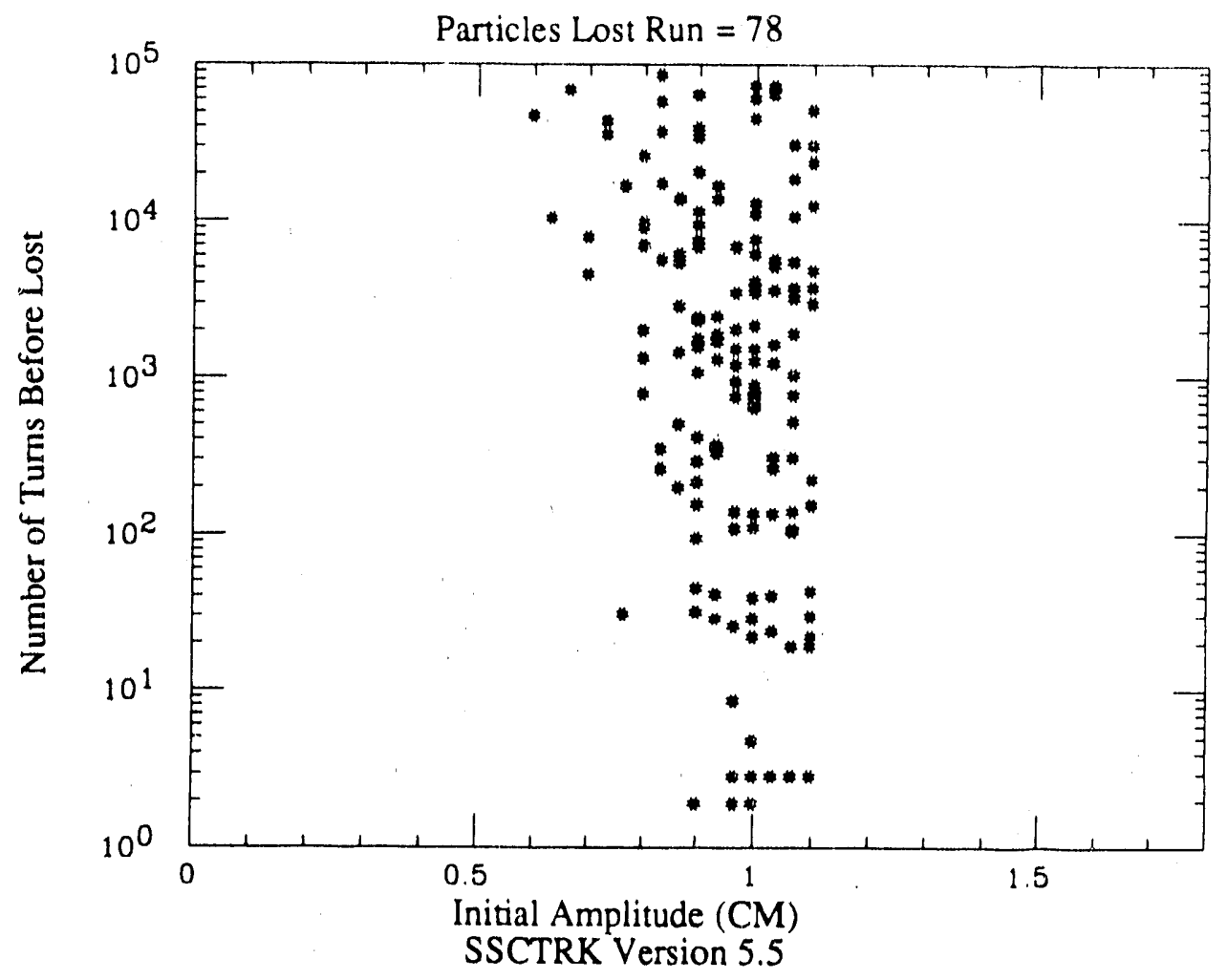

Run 78 is $10^{5}$ turns of 16 highly corrected machines of $4 \mathrm{crn}$ magnet aperture. The particle loss plot shows a dynamic aperture of about $9 \mathrm{~mm}$ after a few turns and about $6 \mathrm{~mm}$ after $10^{5}$ turns.

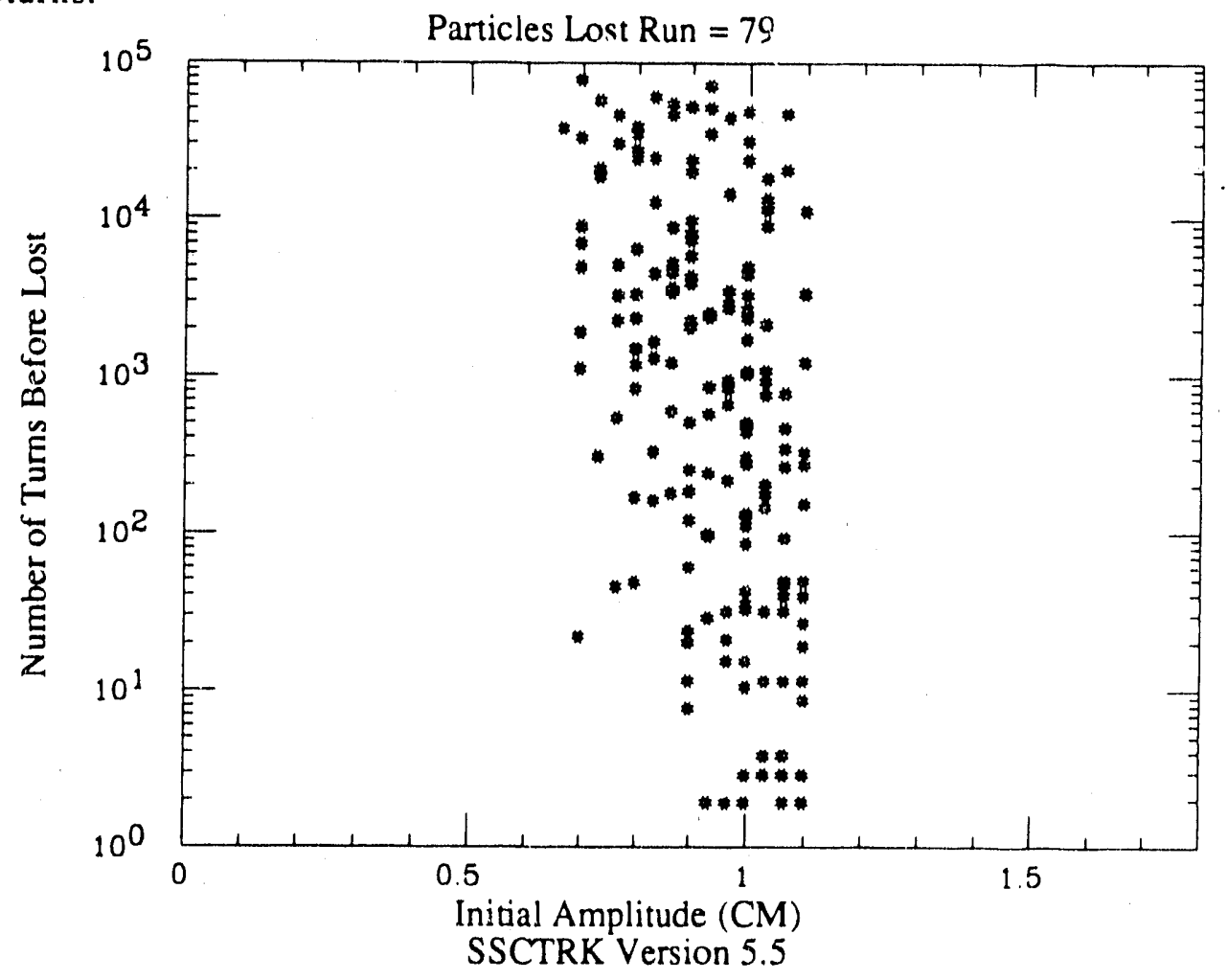

Run 79 is the same as run 78, except that the random regular sextupcle error was increased to its nominal SSC-7 value, i.e. dipole sorting on this random multipole was no longer assumed. There is no significant difference to run 78 . 

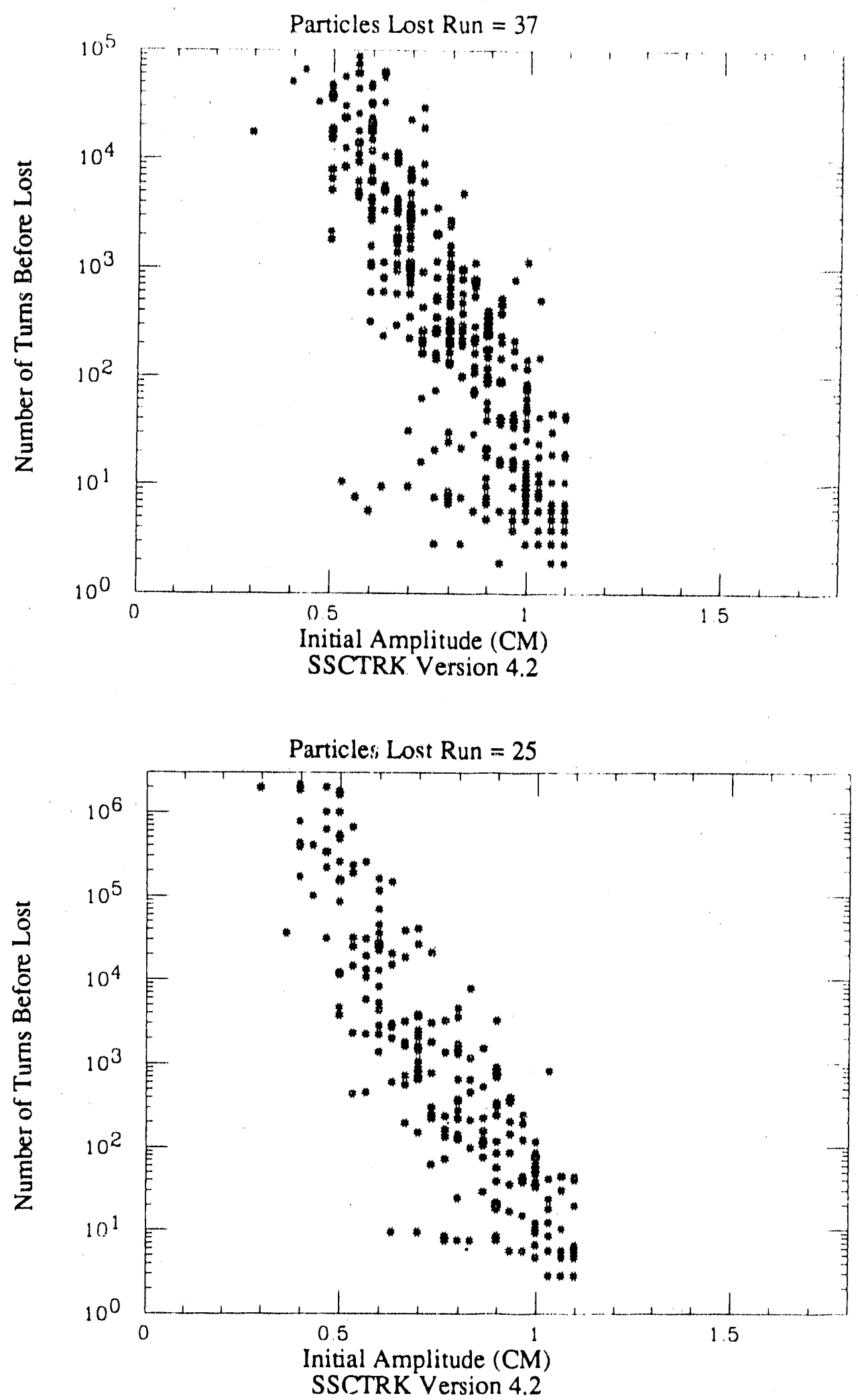

Run 37 as shown in previous run is $10^{5}$ turns of 16 plausibly corrected machines of $4 \mathrm{~cm}$ magnet aperture (systematic errors from Table 2 together with +5 units of $x$ and $y$ chromaticity). The dynamic aperture has dropped to about 3 to $4 \mathrm{~mm}$, in contrast with the $6 \mathrm{~mm}$ for the highly corrected machines of run 78. The same picture shows up in run 25 , which has the same parameters as run 37 , but with only eight machines run out to $3,000,000$ turns. 


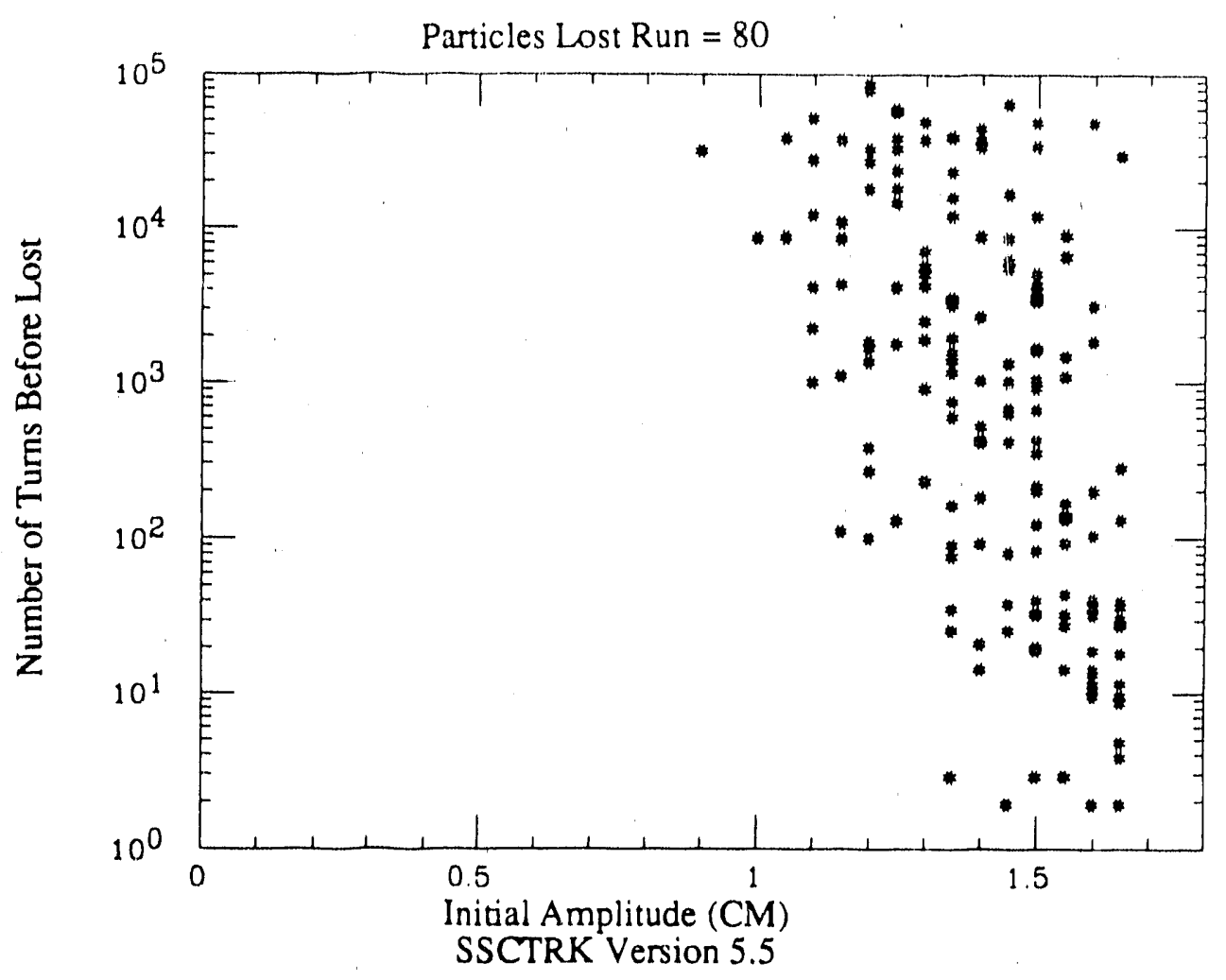

Run 80 is $10^{5}$ turns of 16 highly corrected machines of $5 \mathrm{~cm}$ magnet aperture. Here the four first generation particles are gridded at $15 \mathrm{~mm}, 15.5 \mathrm{~mm}, 16 \mathrm{~mm}$ and $16.5 \mathrm{~mm}$, and subsequent generations are stepped in by $1.5 \mathrm{~mm}$. The dynamic aperture for 100,000 urns is about $9 \mathrm{~mm}$.

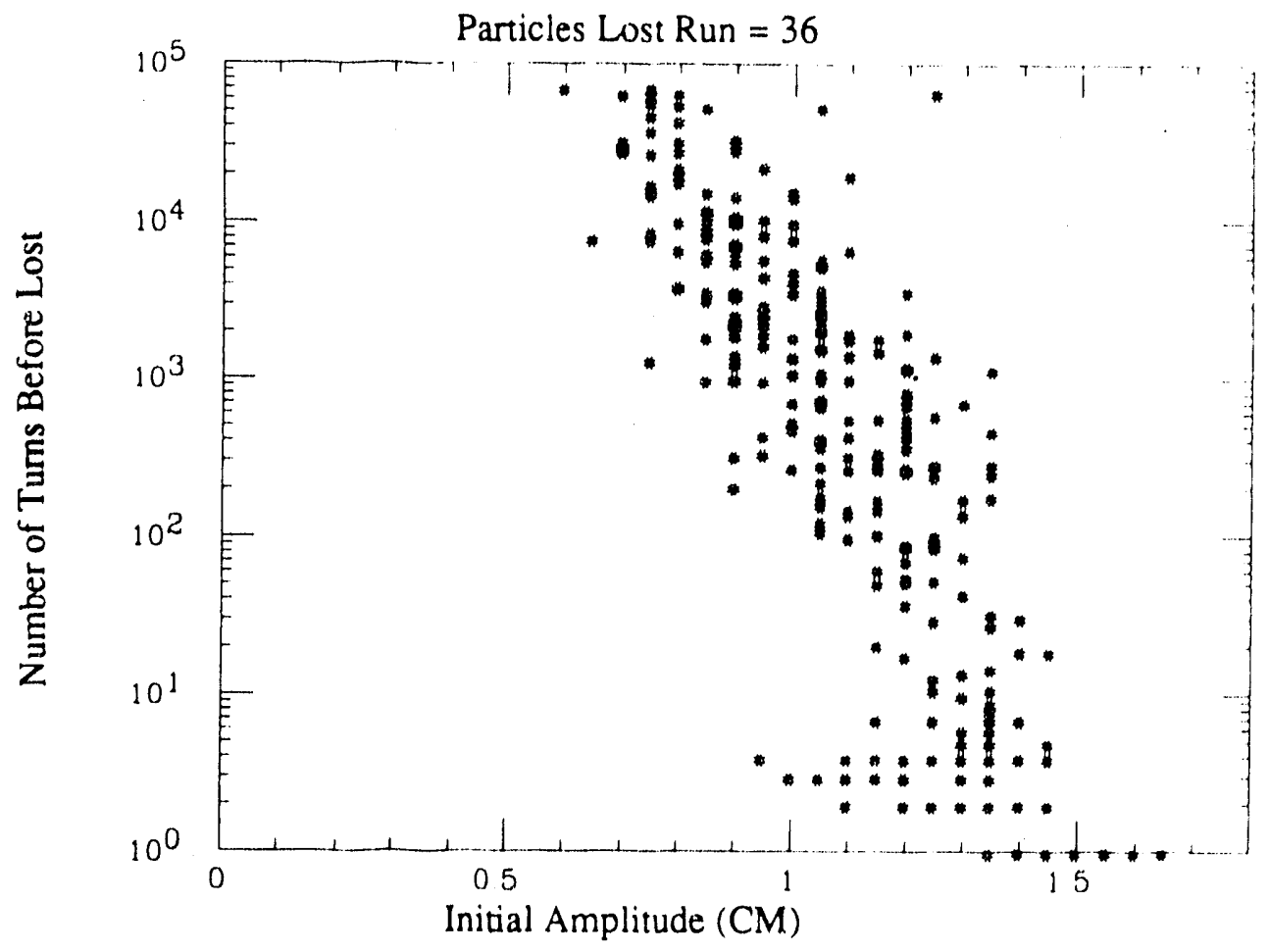

Run 36 is 105 turns of 16 plausibly corrected machines of $5 \mathrm{~cm}$ magnet aperture. The dynamic aperture for 100,000 turns is about $6 \mathrm{~mm}$. 

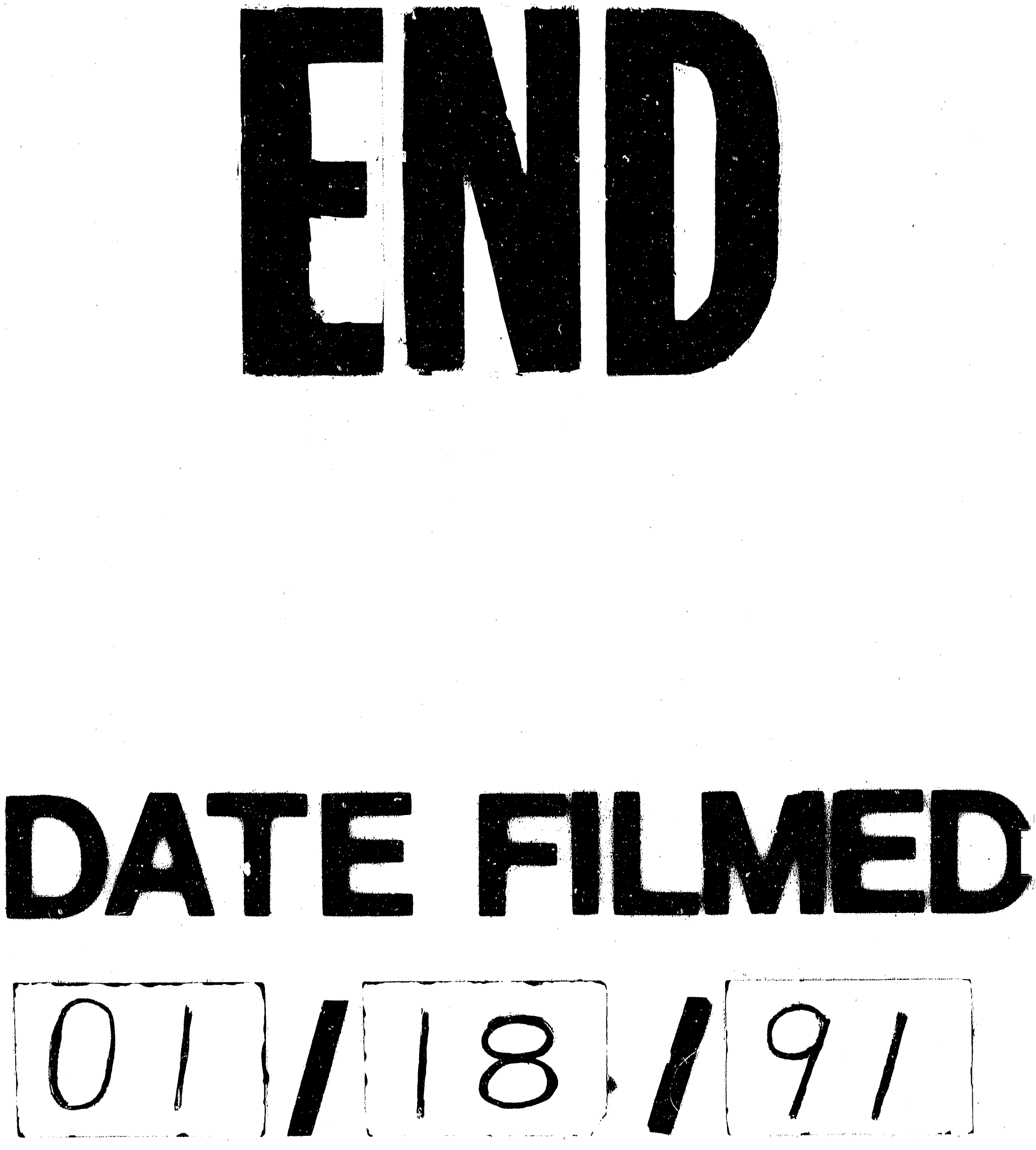
